\title{
Simulation Applied To Urban Logistics: A State Of The Art
}

\author{
Sarra JLASSI, MINES ParisTech, PSL Research University, Centre de Robotique \\ Simon TAMAYO, MINES ParisTech, PSL Research University, Centre de Robotique \\ Arthur GAUDRON, MINES ParisTech, PSL Research University, Centre de Robotique
}

KEYWORDS: urban logistics, simulation, state of the art, literature review.

\begin{abstract}
This work provides a review of simulation techniques applied to urban logistics with a focus on practical applications. Several techniques and tools have been proposed to simulate different systems in urban logistics. In most cases, simulation choices depend on the objective of the simulation, the role of the decision maker and the type of problem. The paper offers a state of the art in which we analyse the existing simulation solutions for a given problem and/or a given stakeholder. As a result, it offers a practical reference for urban logistics researchers and practitioners who wish to use simulation in order to study the behaviour and performance of their systems. We propose an analytical framework allowing an easy overview of advantages and drawbacks of each technique, output criteria and examples.
\end{abstract}

\section{INTRODUCTION}

The world's global population is increasingly concentrating in cities, $52 \%$ of the population currently lives in urban areas and by 2050 this number is expected to reach $67 \%$ (World Urbanization Prospects, 2014). Urban logistics becomes a major issue of interest for both municipal authorities and the Transport \& Logistics Industry. For people, urban logistics ensures the supply of goods in stores and for firms it forms a vital link with suppliers and customers (Crainic et al., 2004). For local authorities, the inexpensive and quick movement of goods is crucial for ensuring that their cities remain competitive, attractive and environmentally friendly. For logistics providers and transporters, last-mile logistics can be expensive and complex to manage, especially with the growth of new channels of distribution notably e-commerce (see Durand et al., 2012). In the last decades, a notable increase in the number of vehicles is noticed as well as a saturation of transportation infrastructures (Cagliano et al., 2014). Consequently, congestion, noise, accidents, transportation delays, infrastructure degradation, and polluting emissions are some of the most serious problems transportation and city managers have to deal with.

As the importance of urban logistics increases several authors have explored best practices, regulatory measures and organization schemes for improving urban freight in terms of cost, traffic congestion, logistic efficiency, environmental nuisances, or other criteria depending on the stakeholders taken into account. In order to address these stakes, many modelling techniques have been implemented and documented (Bozzo et al., 2014, Comi et al., 2014). Nonetheless, in many cases the developed models do not lead to simulation applications. 
The paper proposes a state of the art of the existing simulation techniques in the field of urban logistics. Section 1 aims at clarifying the ambiguity between the concepts of modelling and simulation. A brief review on the main models related to urban logistics in Europe is given. In section 2, the method used for literature review is described. Section 3 proposes a review and classification of the publications dealing with simulation in urban logistics. A synthetic view is presented as a table, where each reviewed publication is characterized in terms of scope, stakeholder and output. After exploring the literature referring to simulation in urban logistics, it was observed that the number of papers ending up with real simulation applications is limited. In this context, our contribution is to propose an analytical framework allowing an easy overview of the existing simulation techniques, their inherent choices and their advantages and drawbacks. This framework, described in section 4, examines the choices of simulation techniques carried out in the different publications, the typologies of problems that are approached with similar simulation tools and the software solutions chosen by the authors. A synthesis of the opportunities for simulation in urban logistics is proposed and finally the last section provides some final conclusions and directions for future work.

\section{Modelling Vs Simulation}

It is important to distinguish between modelling and simulation. A model is a representation of a system. It can be described qualitatively with an influence diagram or quantitatively using mathematics. The model is similar to but simpler than the system it represents (Maria, 1997). A good model is a judicious trade-off between realism and simplicity. A simulation is the operation of the model. It is the process of using a model in order to understand how systems behave over time and to estimate and evaluate their performances. As described in (Garrido, 2011) the notion of simulation relates to a set of techniques, methods, and tools for developing a simulation model of a system and using and manipulating such model to gain more knowledge about the dynamic behaviour of the system. In simpler words, simulation consists in asking "what if" questions about the real system and observing the impacts of variables change over time on the behaviour of the system. From this standpoint, simulating implies modelling, but modelling does not necessarily imply simulating.

Important models have been developed in the field of urban logistics, particularly to estimate movements of goods. Two of the most present models in the literature are the models WIVER and FRETURB. The WIVER model, developed in Germany by Sonntag (1985), produces O/D matrices for road-based urban goods movements and other commercial related activities. The FRETURB model, developed in France by Routhier and Toilier (2007), estimates the movements of commercial vehicles in a given urban area on the basis of a set of socioeconomic variables. Based on the same approach implemented in FRETURB, Gentile and Vigo (2013) developed the CityGoods model in Italy. Since this work's main objective is to provide a review of simulation techniques applied to urban logistics, we will not focus in these models, but rather in their possible application to simulation. Readers interested in models should refer to (Gonzalez-Feliu and Routhier, 2012 and Comi et al., 2014).

\section{RESEARCH METHOD}

The following steps allowed the query and selection of the articles in order to identify the different simulation models and tools applied to urban logistics. First: we identified the noteworthy keywords related to the urban logistics field. These keywords were generated by 
combining the "initial keys" (A) and the "specific keys" (B) shown in Table 1. Querying with these criteria in several databases (Google scholar, Elsevier, Science Direct, Emerald, IEEE, Scopus, AMC and Web of Science) furnished a significant number of studies that were included in an initial meta-analysis. Second: in order to extract studies and articles dealing with simulation we applied a search filter using the boolean function "AND" with the keyword "simulation".

Table 1. Areas of research and resulting simulations techniques

\begin{tabular}{|l|lll|}
\hline INITIAL KEY (A) & SPECIFIC KEYS (B) & & \\
\hline Urban & Logistics & Freight movements & Demand \\
City & Distribution & Freight transport & Traffic \\
Last mile & Delivery & Freight demand & Parking \\
& Planning & Transportation Routing & Commercial movements \\
& Goods distribution & Delivery spaces/areas/bays & Decision support \\
& Goods movements & Loading/unloading bays & \\
\hline
\end{tabular}

This search resulted in a collection of 40 publications that were classified by year of publication, output criteria (measured or evaluated by the simulation), type of stakeholder and simulation technique, as shown in Table 2. Note that several of the reviewed works combine different simulation techniques; thus the total of the right column does not add up to $100 \%$.

Table 2 Distribution of the reviewed papers

\begin{tabular}{|ll|l|l|l|}
\hline YEAR & & OUTPUT & STAKEHOLDER & TECHNIQUE \\
\hline $201612.5 \%$ & $20107.5 \%$ & Economic $92.5 \%$ & Local authorities 75.0\% & Discrete event 35.0\% \\
$201515.0 \%$ & $20097.5 \%$ & Environment. 52.5\% & Carrier 50.0\% & Agent-based 40.0\% \\
$201415.0 \%$ & $20082.5 \%$ & Social $17.5 \%$ & Shipper/Receiver 35.0\% & Monte Carlo 20.0\% \\
$201310.0 \%$ & $200710.0 \%$ & & Residents 10.0\% & Instance generation 22.5\% \\
$201210.0 \%$ & $20057.5 \%$ & & & System dynamics 7.5\% \\
$20112.5 \%$ & & & & \\
\hline
\end{tabular}

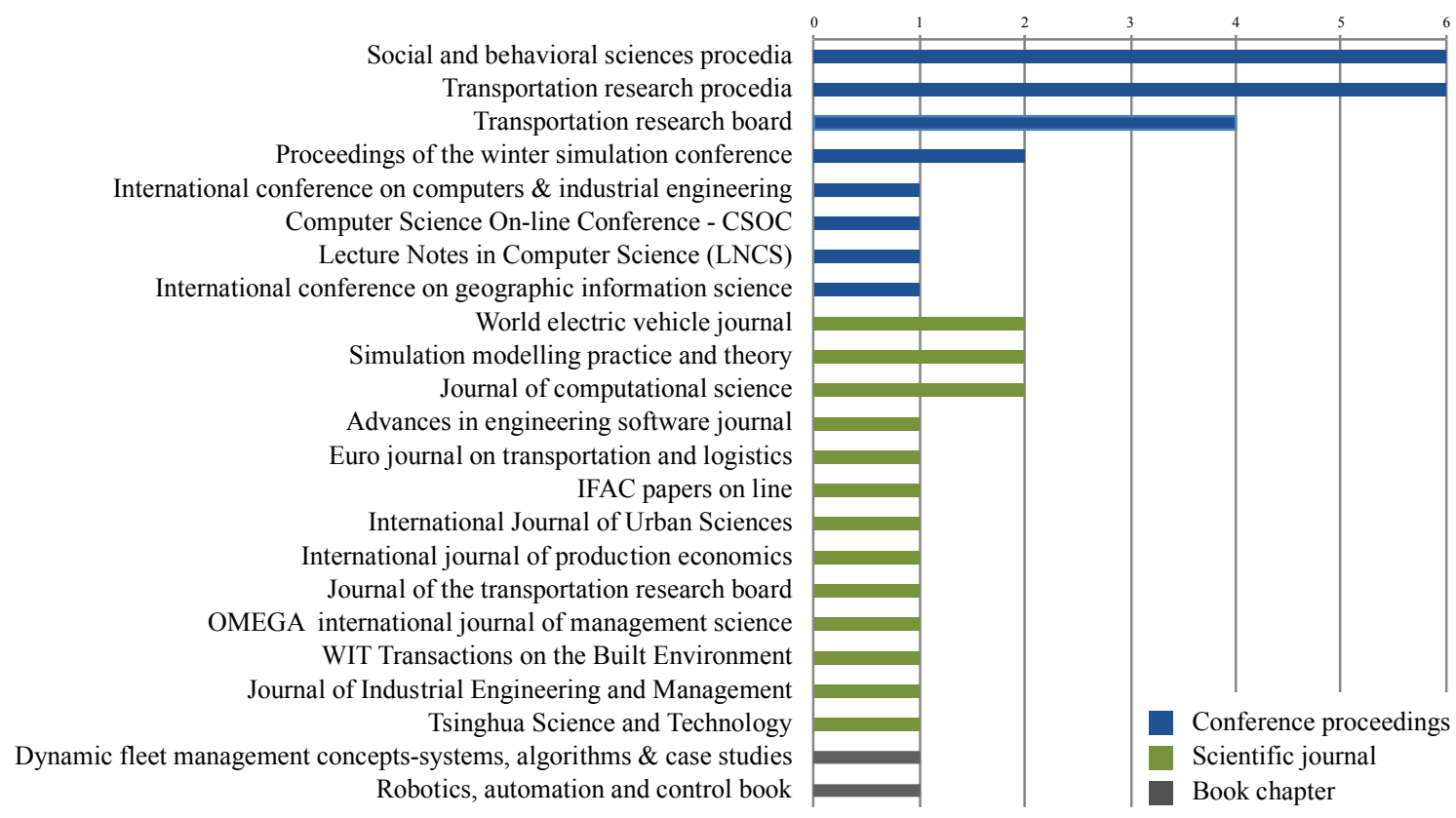

Figure 1. Distribution of reviewed works by type of publication

Note that the first three proceedings account for about $40 \%$ of the total reviewed publications. 


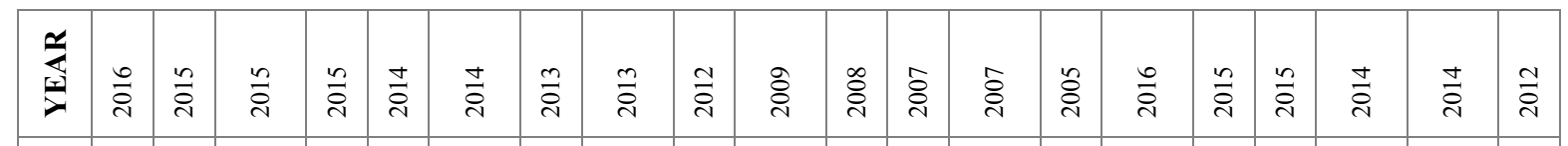

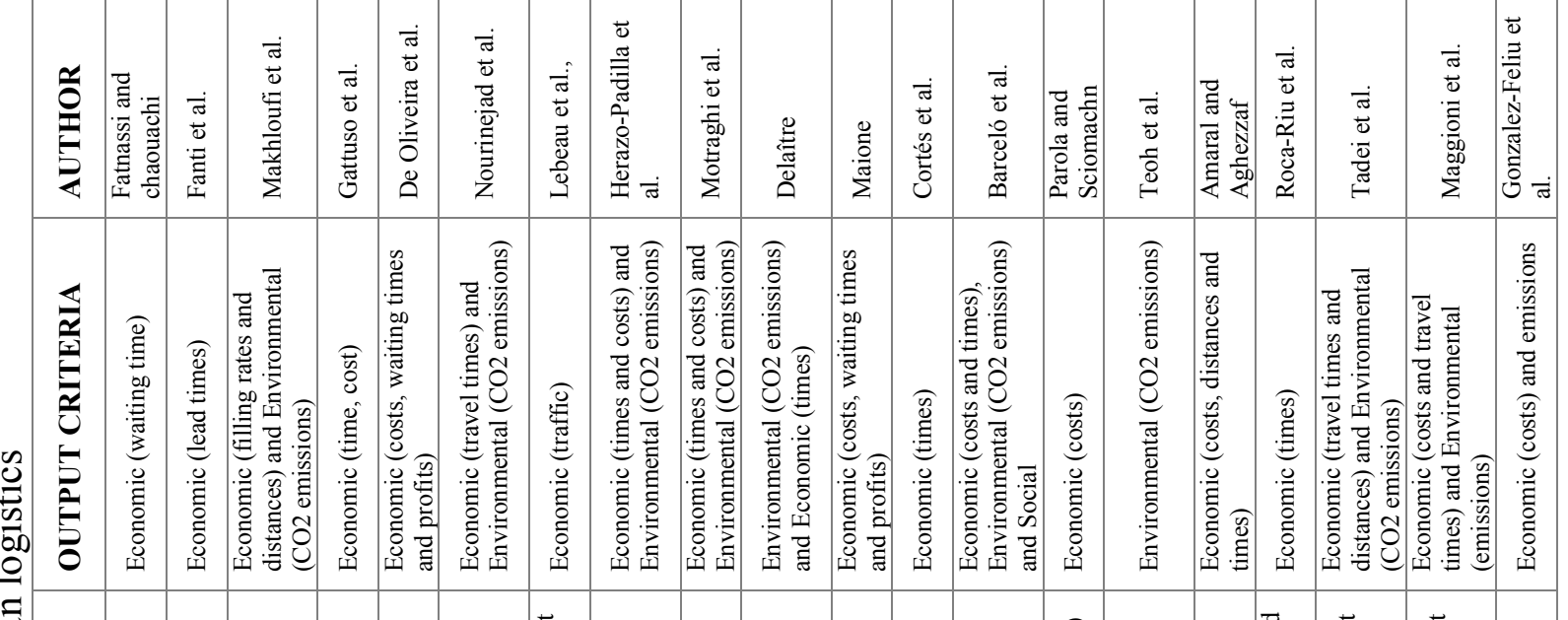

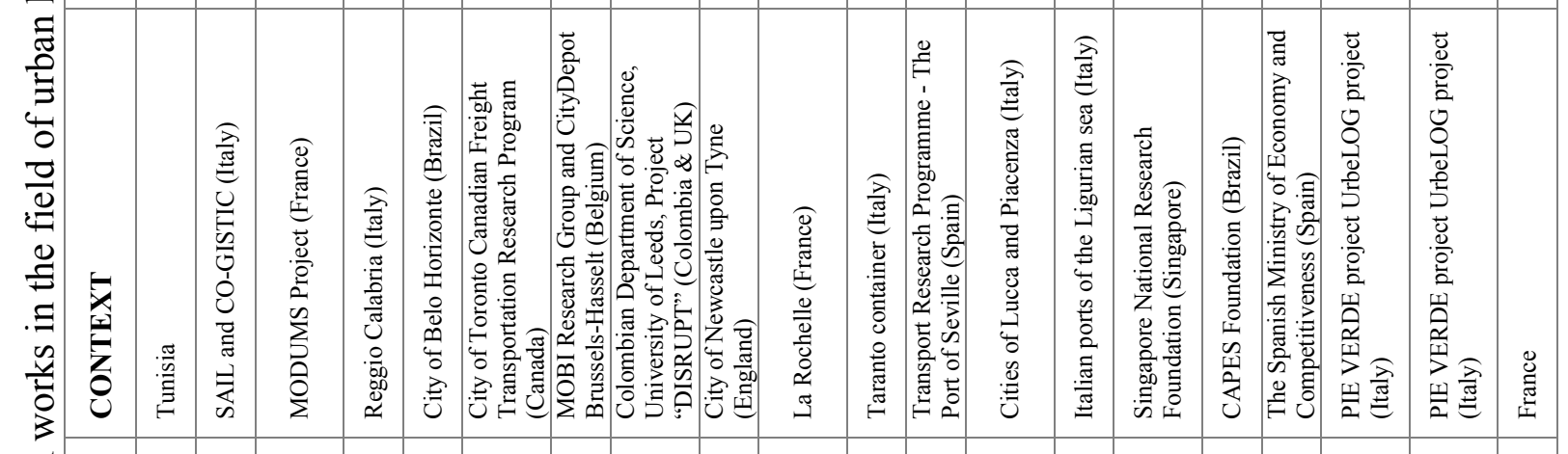

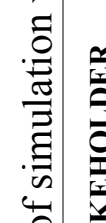

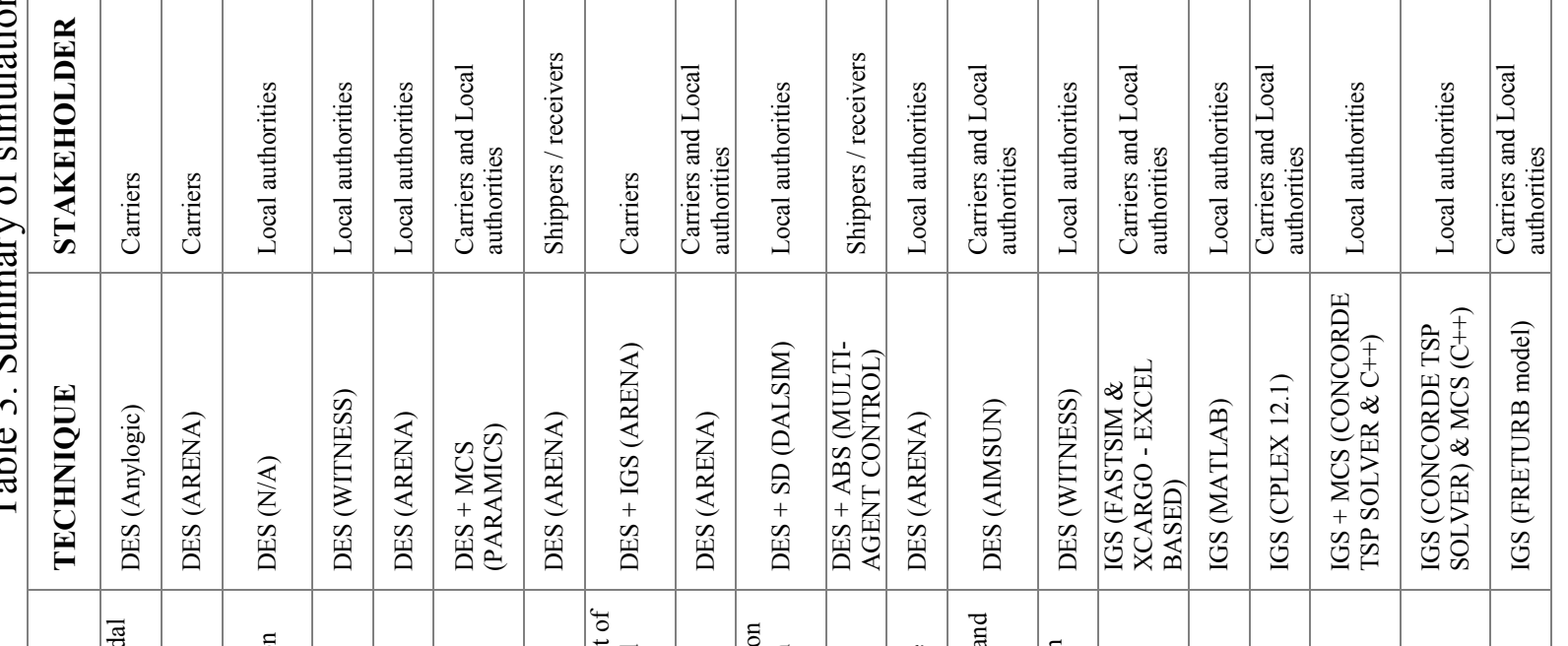

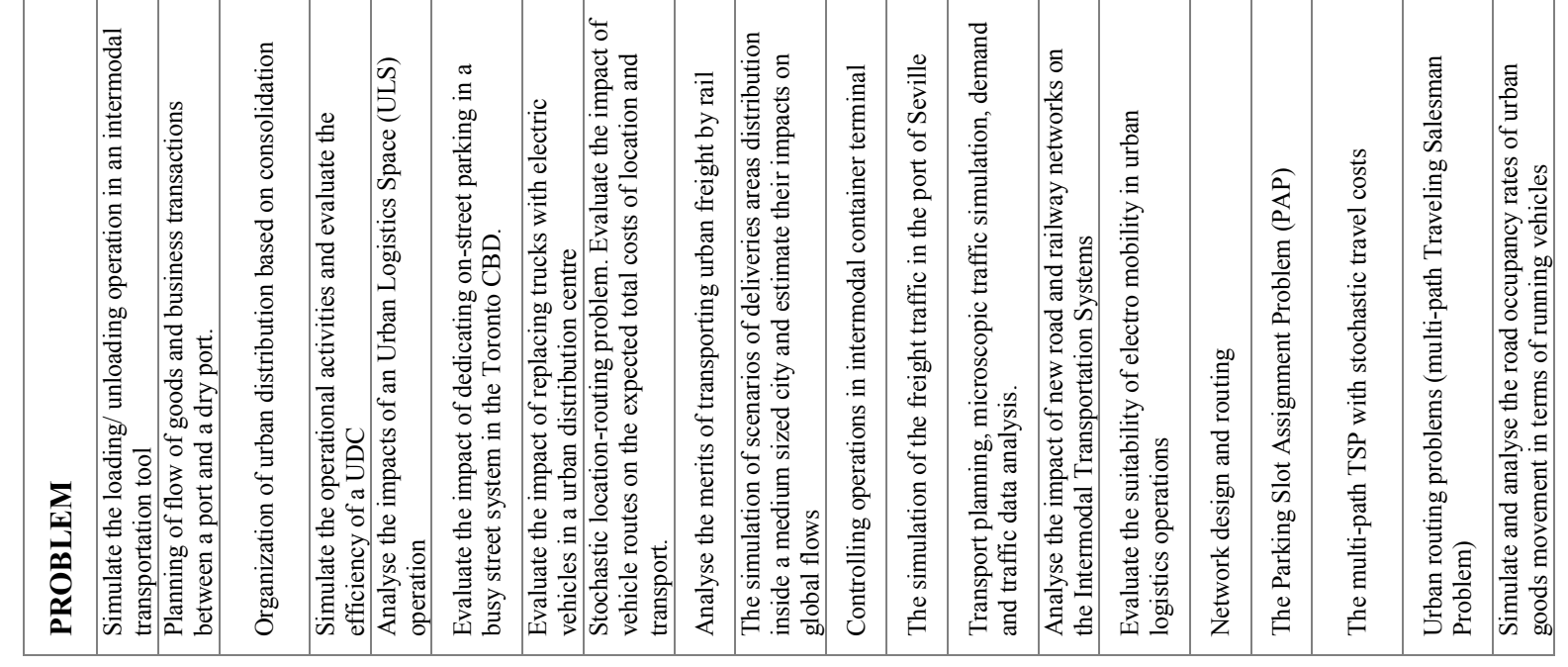




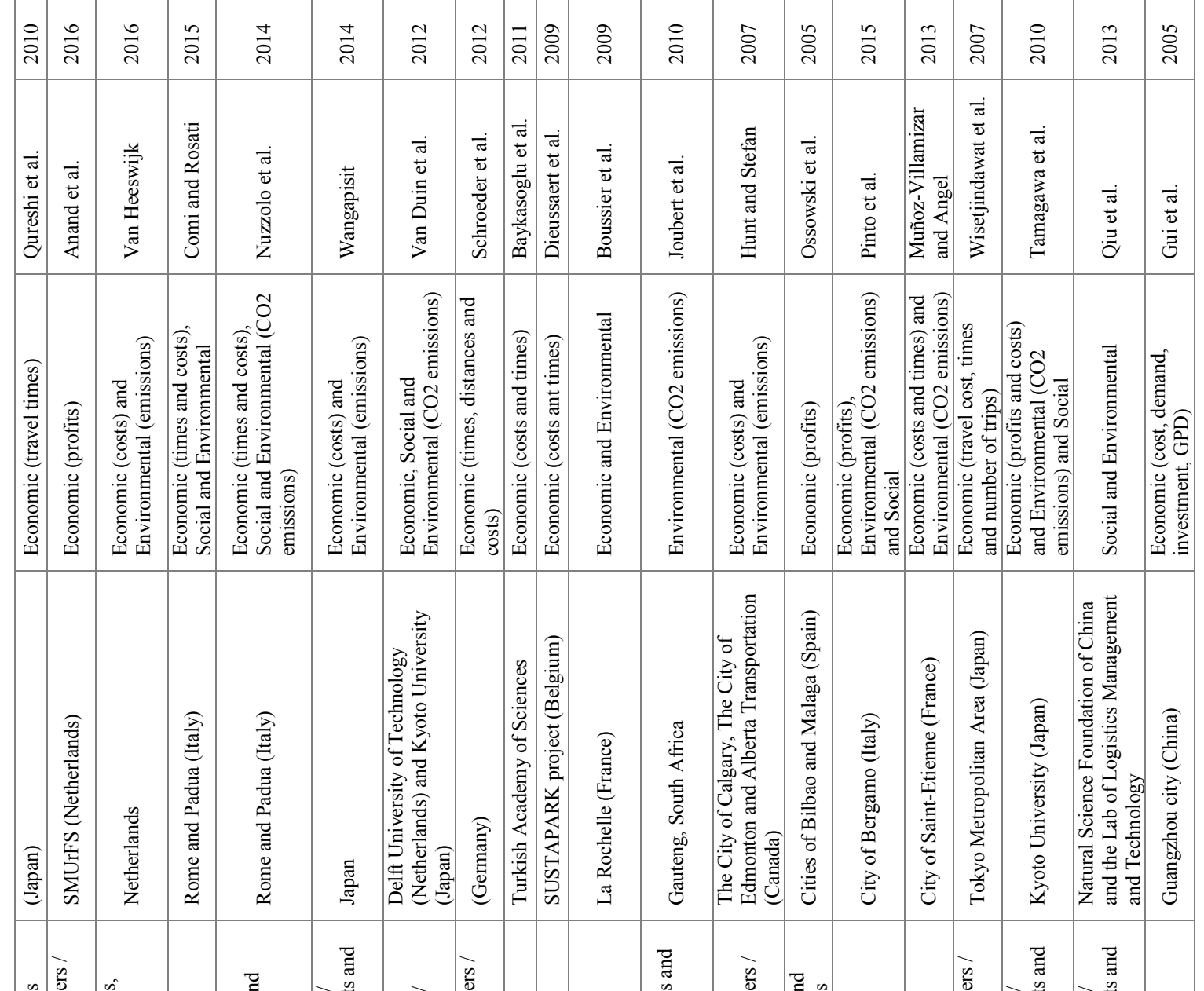

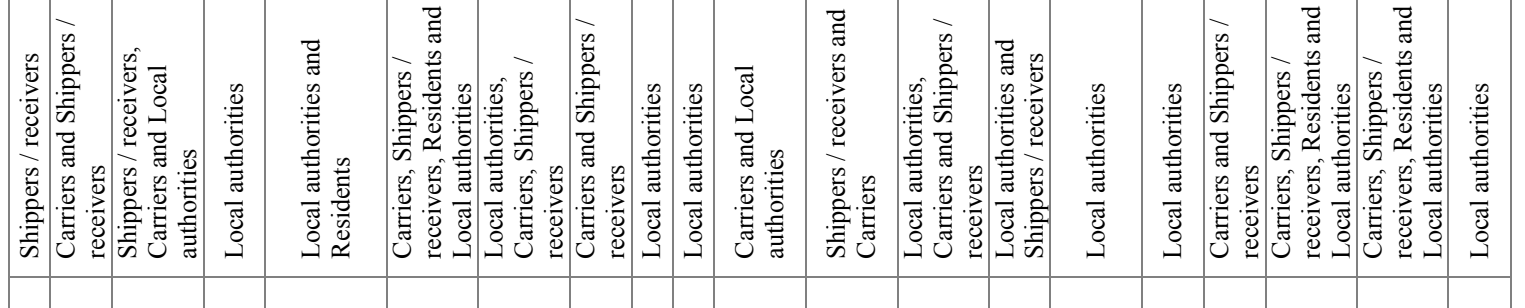

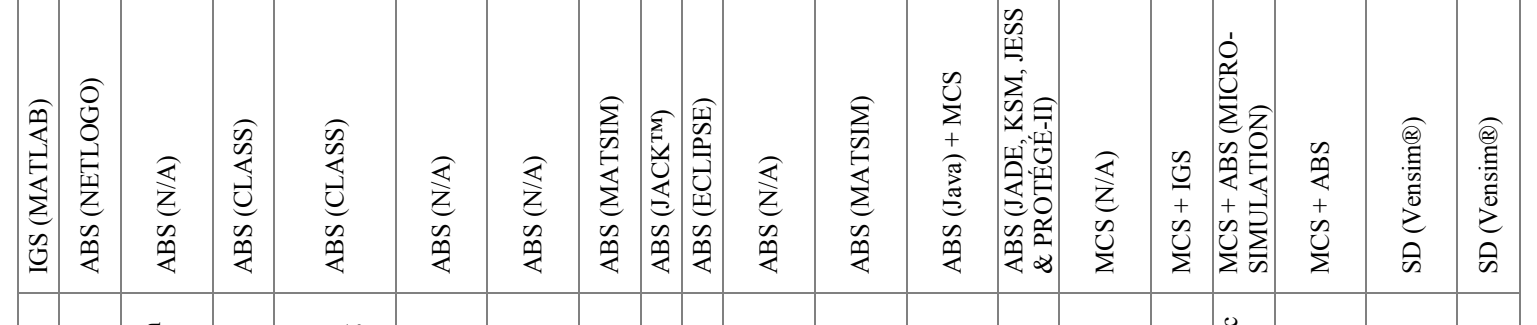

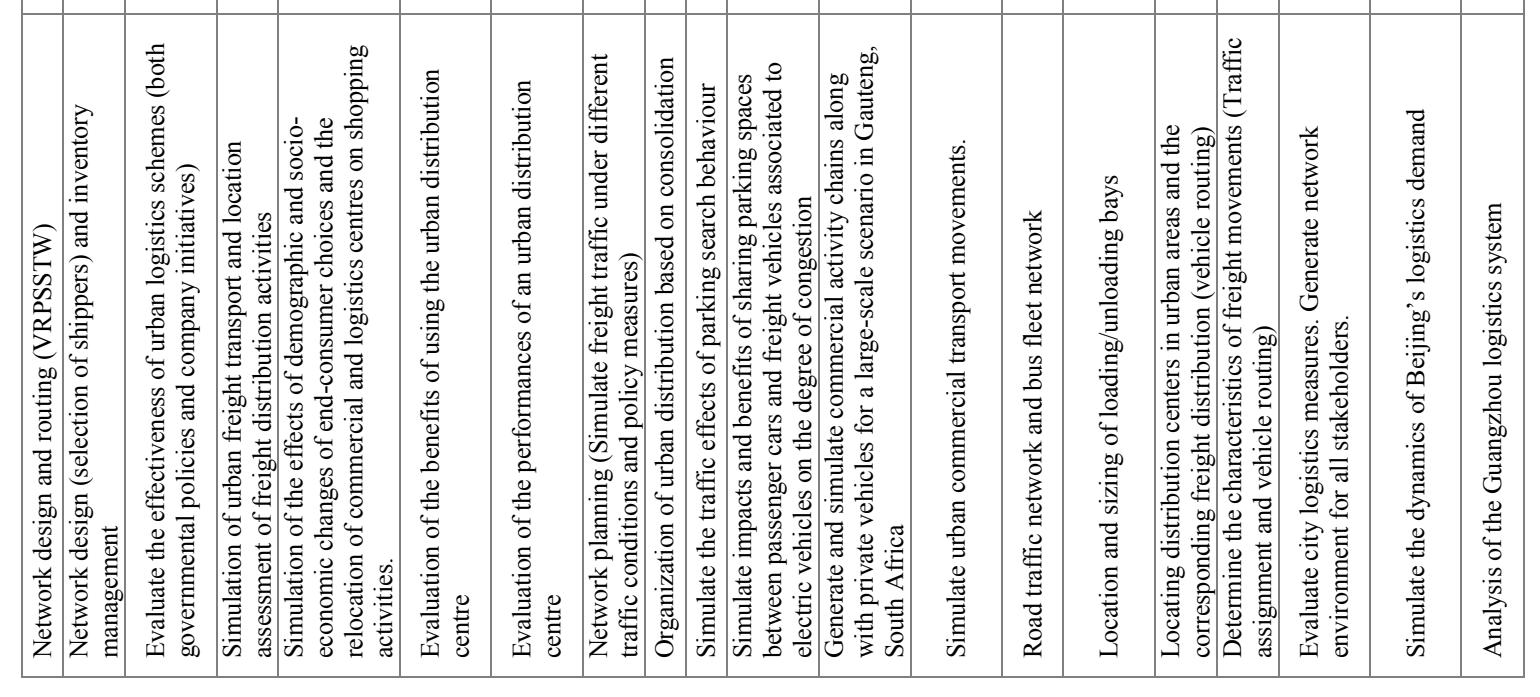


Our literature review shows that most of the simulation works have a local authority standpoint (75\%), some involve private actors, such as carriers (50\%) and Shippers / receivers $(35 \%)$ and few of them involve residents $(10 \%)$. Also, it revealed that five main simulation techniques are used to address urban logistics problems. As shown in Table 3, the main simulation techniques used in urban logistics are:

- Instance generation (IGS): consists in carrying out tests on configurations of a problem (possibly non-exhaustive) in order to assess the performances of a system, its inherent algorithms and/or the impacts of certain parameters.

- Monte Carlo simulation (MCS): makes use of random sampling and statistical analysis to compute results. MCS generates an important number of random configurations of a system sampling from the probability distributions of the events that can occur (Vose, 1996), and furthermore performs statistical analysis in order to obtain significant conclusions.

- Discrete event simulation (DES): is characterized by discrete-state models (as opposed to continuous-state models) in which systems evolve in a discrete space where time is driven by events.

- Agent based simulation (ABS): allows the representation of actions and interactions of autonomous entities that following their own rules and interests (Dieussaert et al., 2009). ABS is well adapted to simulate complex systems where several agents are involved and in which establishing general rules for their interactions is difficult. Time management in this kind of simulation is also discrete: time-driven or event-driven.

- System dynamics (SD): focuses on flows around networks rather than on the individual behaviour of entities (Maidstone, 2012). In SD the real-world processes are represented in terms of three main objects; stocks, flows and delays (Borshchev et al., 2004).

It is to note that these approaches are not mutually excusive, for example, Monte Carlo simulation could be considered as a form of discrete-event simulation. Moreover, these techniques are often combined, as it will be exposed in the next sections.

\section{ANALYTICAL FrAMEWORK}

\section{Simulation techniques used in different types of problems}

Our literature review on papers dealing with simulation in urban logistics highlighted 40 simulated problems that can be classified in 5 categories: (1) Transportation, Network and Infrastructure (TNIP): $52.5 \%$ of the publications (2) Vehicle routing (VRP): $17.5 \%$ (3) Urban Consolidation \& Mutualization (UCMP): $22.5 \%$ (4) Intermodality (IP): $15.0 \%$ and (5) Electromobility (EP): $7.5 \%$.

Several of the reviewed works deal with different problems; as a result, the total of the latter percentages does not add up to $100 \%$. Figure 2 shows, for each type of problem, the frequency of utilisation of each simulation technique. In this section, these different problems are examined and an analysis based on the arguments found in the reviewed papers and on the answers given by the corresponding authors after an email survey is proposed.

\section{Transportation, network and infrastructure problems (TNIP)}

TNIP correspond to the wider category amongst the reviewed problems. They include planning of freight movements and operations in urban environments, traffic management and parking and facilities location. In this category, we counted 21 publications in which ABS is the most used simulation technique followed by DES (see Figure 2, top left). 

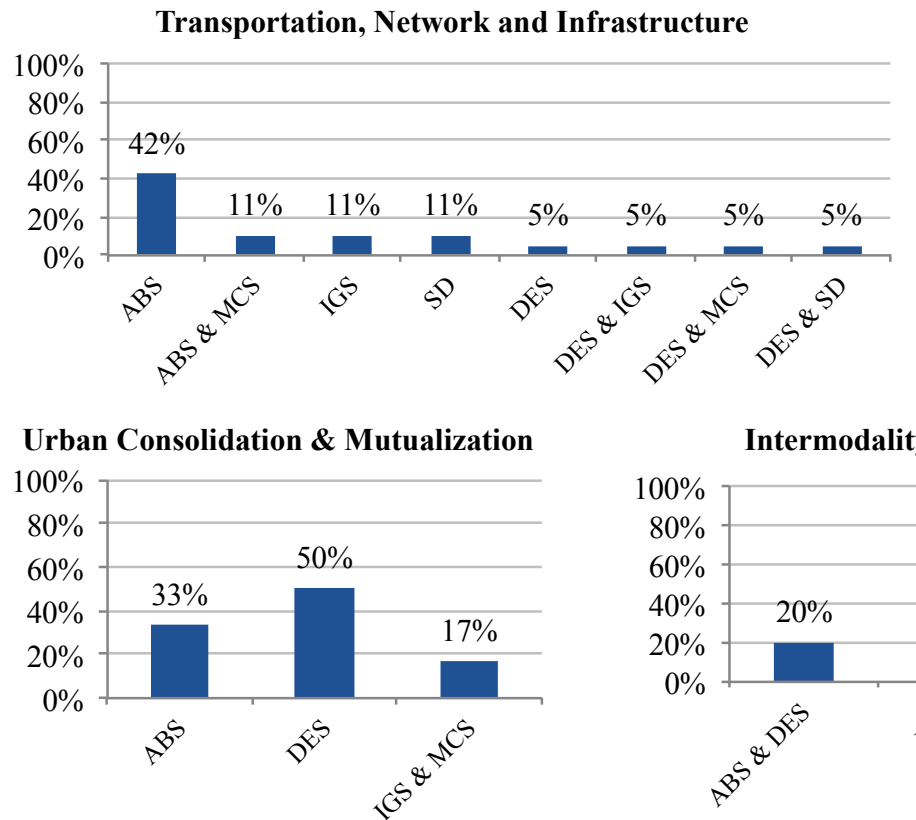
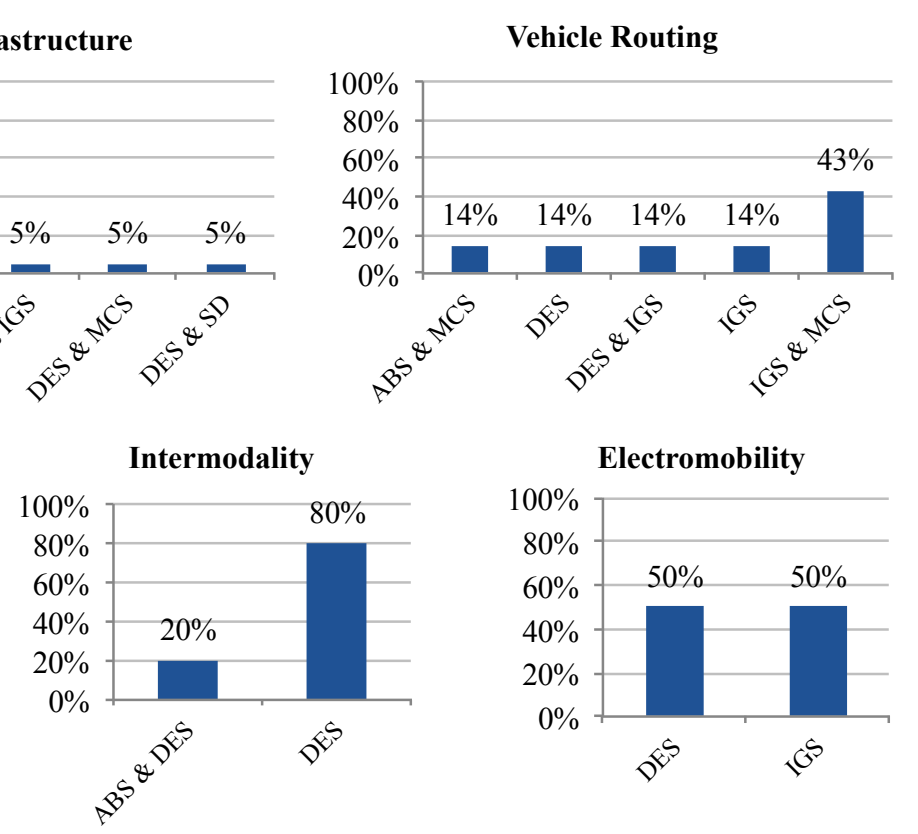

Figure 2. Utilization of simulation techniques when solving the 4 types of problems

9 publications dealing with TNIP implement ABS (exclusive):

- Anand et al. (2016) denoted that ABS is a more natural and flexible technique to model complex systems rather than SD and DES. However, some characteristics of ABS such as their micro-level of operation, the need for explicit interactions and the path dependency of results can make them difficult to apply and to validate.

- Schroeder et al. (2012) justified the use of ABS as it allows the 4 agents (shipper, transport service provider, carrier and driver) to act as independent decision-makers or behave as single entities. Moreover, the ABS can focus on the behaviours of the agents as well as implement notions of market coordination, learning capabilities and limited perceptions.

- Joubert et al. (2010) used an ABS technique to reconstruct commercial activity chains. These chains were simulated using the ABS toolkit MATSim for a large-scale scenario in Gauteng, South Africa. This work, listed three advantages of ABS: (1) they represent the heterogeneous nature of freight transport actors and objects; (2) optimization engines can be incorporated into the individual agents' behavioural models; and (3) micro-model results can be aggregated to support decisions in a more global context.

- Dieussaert et al. (2009) justified the use of ABS on the grounds that it has the advantage of allowing local interactions between the drivers and their environment for the problem of parking search and choice.

- Ossowski et al. (2005) described a design method for building agent-based Decision Support System (DSS) for real-world traffic management problems. They outlined the role of multi-agent techniques in the design and implementation of such tools for the problems of road traffic management.

- Van Heeswijk (2016) highlighted that ABS techniques are suitable to evaluate the effectiveness of urban logistics schemes (both governmental policies and company-driven initiatives), as they are capable of monitoring and altering the behaviour of autonomous agents under varying conditions.

- Nuzzolo et al. (2014) as well as Comi and Rosati (2015) presented DSS based on the ABS tool "CLASS", developed to support ex-ante assessments to simulate goods movements and capture the effects due to urban freight transport measures on end- 
consumer and retailer behaviours. The results of its application to Padua a medium-size town in northern Italy are reported.

- Hunt and Stefan (2007) developed an agent-based micro simulation framework using a tour-based approach of urban commercial transport movements in the region of Calgary.

A combination of ABS and MCS has been implemented in 2 publications:

- Tamagawa et al. (2010) addressed both TNIP and VRP. They presented a methodology for evaluating city logistics measures considering the behaviour of several stakeholders. They proposed a framework based on two sub models: a learning model for stakeholders (using Q-Learning and MCS) and a vehicle routing model. The use of ABS was justified as they considered stakeholders to be independent agents that have their own objectives and behaviours. MCS was used to represent changes in the stakeholder's behaviours after perceiving changes in their environment (e.g. new city logistics measures).

- Wisetjindawat et al. (2007) developed a micro-simulation model for Tokyo Metropolitan area freight. They proposed a hybrid technique (ABS and MCS) in which each freight agent individually determines the characteristics of a set of freight movements, which proved to be representative of a real urban area. The MCS was used to generate virtual firms and their attributes (production, consumption, distribution, etc.).

DES (exclusive) has been implemented in 1 publication:

- Motraghi et al. (2012) dealt with both TNIP and IP. They examined the utilisation of existing urban rail networks for freight distribution in cities. A DES model was developed to study a possible implementation in the Newcastle Metro. The choice of DES was justified on the grounds of simplicity when representing complex stochastic systems.

A combination of DES and MCS has been implemented in 1 publication:

- Nourinejad et al. (2014) developed a traffic simulation module in the "Paramics traffic simulation ${ }^{\circledR}$ ", a microscopic time-stepping DES. This module incorporated a parking choice model in which the implementation of DES is essential for the representation of queues and transitions. In addition to DES, they made use of MCS in order to integrate the parking choice model and to measure the dwell time for each vehicle.

A combination of DES and IGS has been implemented in 1 publication:

- Herazo-Padilla et al. (2013) dealt with TNIP and VRP. They considered the stochastic version of the location-routing problem (SLRP) in which transportation costs and vehicle travel speeds are both stochastic. A hybrid solution procedure based on ant colony optimization (ACO) and DES (using ARENA®) was proposed. DES allowed to evaluate the impacts of vehicle routes on the expected total costs. Computational experiments were carried out using a total of 40 random-generated instances.

SD (exclusive) has been implemented in 2 publications:

- Qiu et al. (2015) proposed a SD model using Vensim ${ }^{\circledR}$ to simulate the dynamics of the logistics demand in the city of Beijing. They used of SD in order to integrate macroeconomic factors (unemployment rate, GDP, population size, productivity, etc.) and operational factors (order production, backlog order, volume of the vehicles, etc.).

- Gui et al. (2005) used SD to analyse the Guangzhou logistics system. The simulation was run using Vensim ${ }^{\circledR}$. Gui et al. mentioned that $\mathrm{SD}$ is more intuitive and understandable than other techniques, as it relies on a consequence chart describing the influence and feedback mechanisms amongst variables.

A combination of DES and SD has been implemented in 1 publication:

- Delaître (2009) developed a hybrid model in order to help local authorities in the sizing and allocation of delivery areas by taking into account the impacts on the global traffic flows. The proposed tool is composed by two modules: a simulation of delivery areas at local level based on queuing systems (DES), and a simulation of the overall traffic spread (SD). 
MCS (exclusive) has been implemented in 1 publication:

- Pinto et al. (2016) addressed the problem of location and sizing of parking lay-by areas. In their approach MSC was used to sample arrival intervals and service times of trucks using the lay-by areas.

IGS (exclusive) has been implemented in 3 publications:

- Amaral et al. (2015) considered a two-tiered system and proposed a two-layered optimization model for the urban freight transport, taking into account delivery timewidows for the coordination of flows. An instance generator has been developed to generate and manipulate different instances of the problem. The choice of IG is supported by the simplicity of this technique when dealing with a large number of parameters. In their case, the travel times and costs are time and vehicle-dependent; as a result, a single instance of the problem will have 1920 independent parameters.

- Roca-Riu et al. (2015) presented the Parking Slot Assignment Problem (PAP), consisting in finding assignments of carriers to parking places that satisfy their time windows requests. In this paper, the authors evaluated and compared experimentally the proposed models by solving a set of test instances using CPLEX. 60 instances were generated in an experimental study in the city of Barcelona (Spain).

- Gonzalez-Feliu et al. (2012) proposed a framework to simulate the impacts that ecommerce flows have on urban road occupancy. The authors instantiated a set of scenarios that consider different population densities and household supply strategies.

\section{Vehicle routing problems (VRP)}

According to our literature review, problems related to vehicle routing are the second most important application of simulation to urban logistics mainly solved using IGS and MCS as shown in Figure 2 (top right). This category gathered 7 publications.

A combination of IGS and MCS has been implemented in 3 publications:

- Tadei et al. (2014) addressed the multi-path TSP with stochastic travel costs. In order to evaluate the stochastic objective function of their problem, they used a MCS implemented in $\mathrm{C}++$. Two instances have been generated and solved using the Concorde TSP solver.

- Maggioni et al. (2014) highlighted that the instances presented by Tadei et al. (2014) do not fully reflect real cases although costs were generated according to realistic rules. In order to fulfil this gap, they have generated new instances based on the real traffic sensor network.

- Muñoz-Villamizar and Angel (2013) addressed the problem of locating distribution centers in urban areas and the corresponding freight vehicle routing. Their algorithm makes use of MCS when dealing with determining the location of depots and assigning each customer to the corresponding depot. IGS was applied to solve the different VRP instances.

IGS (exclusive) has been implemented in 1 publication:

- Qureshi et al. (2010) developed a column generation based exact optimization algorithm for the Vehicle Routing and scheduling Problem (VRSP) with Semi Soft Time Windows. The algorithms were implemented in MATLAB. Computational experiments were carried out using eight test instances based on the Solomon's R101 benchmark.

A combination of MCS and ABS has been implemented in 1 publication:

- Tamagawa et al. (2010) (as presented before) combined ABS and MCS. Their VRP-TWF model plans and implements delivery schedules of trucks for each freight carrier (agent).

DES (exclusive) has been implemented in 1 publication:

- Barceló et al. (2007) proposed a decision tool for the VRP in city logistics and its application to the delivery of goods in two Italian cities. The simulator used was AIMSUN® NG, TSS 2005, a microscopic DES program. The detail level of DES allowed 
the approach of specific problems such as VRP with Time Windows (VRPTW) and a Pickup and Delivery Problem with Time Windows (PDPTW).

A combination of DES and IGS has been implemented in 1 publication:

- Herazo-Padilla et al. (2013) (as presented before) addressed the location-routing problem (SLRP) with DES and IGS. In their approach, Ant Colony Optimization metaheuristics were used to solve the VRP. Computational experiments were carried out using a total of 40 random-generated instances

\section{Urban consolidation \& mutualisation problems (UCMP)}

This category includes publications about urban consolation, pooling and mutualisation of resources and/or infrastructure. These problems relate specially to urban consolidation centres UDC and urban logistic spaces ULS. Our review counted 9 publications.

ABS has been implemented in 4 publications:

- Baykasoglu et al. (2011) proposed a novel multi-agent based general load consolidation system for solving dynamic truckload consolidation problems. The proposed system was implemented within JACK ${ }^{\mathrm{TM}}$ an agent-oriented environment integrated with Java.

- Van Duin et al. (2012) used ABS to evaluate the performances of an UDC. The use of ABS was justified as it allows an explicit modelling of individual stakeholder behaviour and actions, which has impact on the overall outcome of the model.

- Wangapisit et al. (2014) used ABS to study the effects of city logistics measures such as urban distribution centres (UDC) and parking space restrictions. The ABS technique was used to represent the multi-objective environment of the different stakeholders and to finetune the parameters of UDC.

- Boussier et al. (2009) designed a software tool for the management of goods distribution in small and medium size cities using electric vehicles. They focused on the management process of parking spaces. ABS was used to simulate impacts and benefits of sharing parking spaces between passenger cars and freight vehicles.

DES (exclusive) has been implemented in 5 publications:

- De Oliveira et al. (2014) proposed a simulation of an Urban Logistic Space (ULS) in central area of Belo Horizonte using Arena $\AA$. They generated indicators to evaluate the performance of this space according to different operating configurations.

- Makhloufi et al. (2015) developed a discrete event simulator (MODUMS) in order to evaluate the pertinence of UDCs located in the outskirts of the city and connected by a ring in a medium-size European city.

- Lebeau et al. (2013) addressed both UCMP and EP (electro mobility). They evaluated the introduction of electric vehicles in urban distribution centres. Input data from CityDepot in Hasselt was used to model this system with Arena ${ }^{\circledR}$. The use of DES is justified on the grounds of their capacity for detecting layout problems and bottlenecks in the system.

A combination of MCS and IGS techniques has been implemented in 1 publication:

- Muñoz-Villamizar and Angel (2013) (cf. previous description).

- Gattuso et al. (2015) proposed a methodology to analyse the problems related to the functional organization of a UDC through a micro-simulation approach using WITNESS. The proposed model is a decision support tool for operators of existing UDC, since it enables them to define the layout, to dimension the internal spaces of the UDC and to evaluate its efficiency.

\section{Intermodality problems (IP)}

Intermodal Transportation Systems are logistics networks integrating different transportation services, designed to move goods from origin to destination in a timely manner 
and using multiple modes of transportation (Dotoli et al. 2010). This category was discussed in 6 publications.

DES (exclusive) has been implemented in 5 publications:

- Fatnassi and Chaouachi (2016) used DES technique with Anylogic ${ }^{\circledR}$ to evaluate loading/unloading operations in the context of intermodal transportation and resources pooling, they considered the case of train and freight-rapid-transit (FRT).

- Fanti et al. (2015) developed a decision support tool to manage the flow of goods and the business transactions in logistics networks composed by a port and a dry port. DES was presented as well adapted for representing Intermodal Transportation Systems (ITS). They explained that ITS are logistics networks systems whose dynamics depend on the interaction of discrete events, such as demands, departures and arrivals.

- Cortés et al., (2007) used DES (Arena $\left.{ }^{\circledR}\right)$ to analyse the freight traffic in the Seville inland port. The approach integrated all the types of cargo (e.g. containers, cereals, cements, etc). Authors justified the use of DES on the grounds of its easiness to provide operational indicators such as crane performances and berth occupations.

- Parola and Sciomachen, (2005) used a DES (Witness ${ }^{\circledR}$ ) model to analyse the impact of new road and railway networks on the logistics system in the intermodal chain of the Italian ports. DES was chosen because of its capacity to represent synchronous processes between the handling resources and the arrivals and departures of vessels, trains and trucks.

- Motraghi et al. (2012) (cf. previous description).

A combination of DES and ABS techniques has been implemented in 1 publication:

- Maione (2008) proposed a multi-agent system architecture for controlling operations in intermodal container terminal systems. The interactions between agents were modelled according to the DES formalism to describe the discrete and independent actions of agents.

\section{Electromobility problems (EP)}

The use of zero emission vehicles is one of the solutions proposed to deal with pollution (emissions), noise and other nuisances due to freight transportation in city centres. Three of the reviewed papers use different techniques (respectively IGS, DES and ABS) to deal with this topic:

- Teoh et al. (2016) developed a methodology to evaluate the operational suitability of electro mobility concepts for last-mile delivery. IGS was used to validate the methodology through two key outputs: accuracy of the energy estimation (FASTSim - Excel-based) and comparing scheduled and routing performance (computed with XCargo logistics software) in regards to real data. It is important to mention that authors pointed out that this work could be done using an agent-based simulation to identify correctly the roads or lanes to be electrified.

- Lebeau et al. (2013) (cf. previous description).

- Boussier et al. (2009) (cf. previous description).

\section{Software solutions}

The Figure 4 provides a synthesis of the software used in the reviewed works. It is important to highlight that various publications do not specify the software solution choices. Arena ${ }^{\circledR}$, a flow-chart based DES environment (see Readiness et al., 2012), is the most used tool in the reviewed publications. Surveys on simulation software (ORMS, 2015; Abu-Taieh, 2005) show that the usability of Arena $\AA$ is an attractive feature (easy to use with available reference literature). Fanti el al. (2015) justified the use of the Arena on the grounds of its capacity for dealing with large-scale and modular systems. We performed a survey amongst the authors of the reviewed publications that use Arena ${ }^{\circledR}$ to understand why they choose this 
tool. The common answer is that they were Arena ${ }^{\circledR}$ users beforehand, although they consider Simul8, Simio, Witness and Anylogic to be software solutions of similar quality.

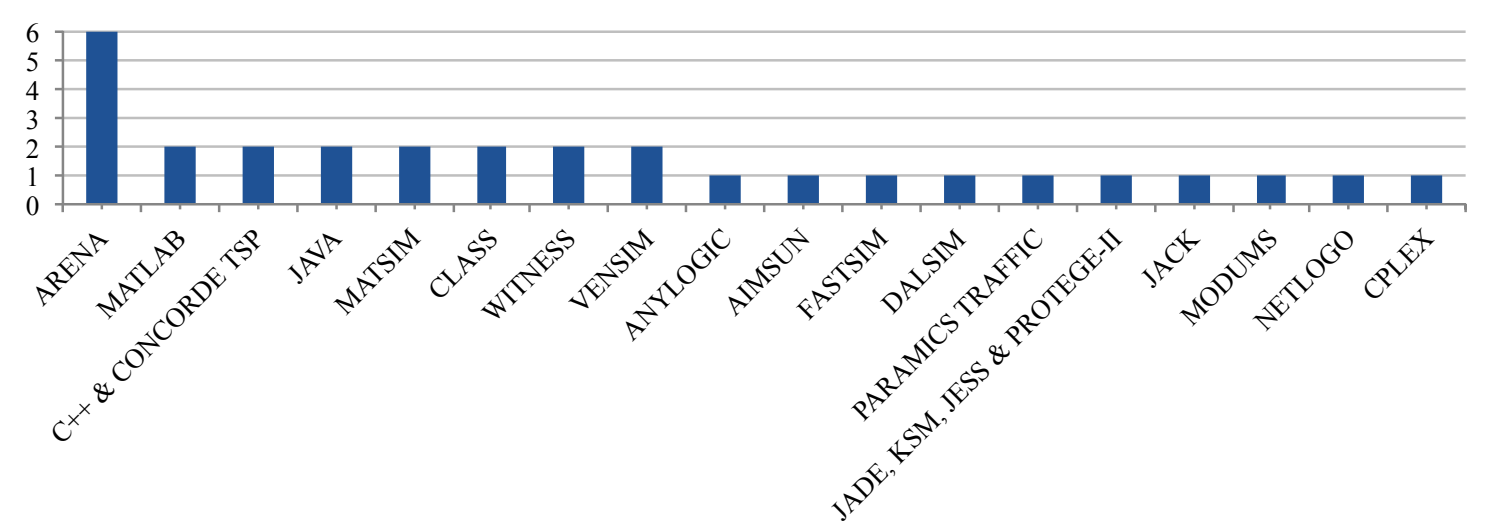

Figure 4. Software solutions used in the reviewed articles

\section{Research opportunities: what remains to be simulated?}

This literature review points out several opportunities for simulation in urban logistics. One important gap relates to the lack of traffic micro-simulation, which could simulate the impacts of urban freight on traffic. This can be explained because of the complexity of traffic simulation and the lack of information on real freight transport.

Although e-commerce is growing fast and is a quite visible aspect of urban logistics, few simulations have been done in this field. A perspective of research could be simulation of how the infrastructures of cities can undertake the growth of logistic operations related to ecommerce. More precisely, simulation in this field could assess the pertinence of new distribution models as well as their environmental impacts.

A primary source of debate in urban logistics is the pertinence of regulations regarding vehicles (sizes, weights, load factors and/or engine types) and restrictions of access (restricted areas and/or time windows). These topics are capital for both practitioners and local authorities. Simulation would certainly help to better understand the impacts of these regulations on each actor of a city.

Many countries are testing alternative fuel vehicles including electric vehicles, hybrid vehicles, natural gas vehicles, and fuel cell vehicles; indeed urban logistics operations are directly affected by these trends. In this field, simulation could be useful to study the needs and investments (infrastructure and/or fleets) in order to ensure a flawless evolution towards greener energies.

In general, we notice the absence of statistical analysis in order to validate the reviewed simulations. Statistical examination of the inputs and the data would allow a better definition of the model's limits and a most relevant interpretation of its results.

\section{CONCLUSION}

In the light of the reviewed publications, different techniques for simulating urban logistics systems can be distinguished. Agent based simulation (ABS) and Discrete Event Simulation (DES) are the most broadly used simulation techniques.

ABS is useful to better understand real-world systems in which the representation or modelling of many individuals is important and for which the individuals have autonomous behaviours. As a result, ABS is gaining more and more interest in urban logistics as it allows 
the interaction between different urban entities (freight carriers, truck drivers, retailers and local authorities) and it allows evaluating and improving the objectives of different stakeholders. Nonetheless, agent based modelling can be harder to develop (Lebeau et al., 2013). Several applications of ABS studying the performances of urban distribution centres can be highlighted in the literature. ABS is particularly useful when there is little knowledge about the global interdependencies between coexisting stakeholders in an urban zone. Our literature review shows that works aiming to evaluate the performances of urban distribution centres are usually tackled with ABS (see Lebeau et al., 2013) or DES (De Oliveira et al., 2014). For further understanding of the main advantages of ABS compared to other techniques, refer to Siebers et al. (2010).

The wide presence of DES could be explained by the large availability and experience of the operational research community with DES software. In urban logistics DES techniques are mainly used to simulate systems involving traffic and lead times, this can be related to the capability of DES to deal with queuing structures. Siebers et al. (2010) described DES as useful for problems containing networks of queues. It is interesting to note that all the reviewed papers dealing with intermodal transportation systems (ITS) make use of DES as simulation technique. ITS are logistics networks systems whose dynamics depends on the interaction of discrete events, such as demands, departures and arrivals of means of transportation at terminals and acquisitions and releases of resources by vehicles and thus can be successfully modelled as Discrete Event Systems.

Monte Carlo Simulation (MCS) has been applied to a diverse range of problems in urban logistics. This technique seems to be a good answer to problems with significant uncertainties, whenever there is need of estimations, forecasts and/or decisions. Most of the reviewed publications use MCS to simulate the variability of urban freight demand, behaviour of actors, and duration of operations. The main applications involve facility location decisions and scheduling. For further reading on the advantages of MSC refer to Raychaudhuri (2008).

Instance Generation Simulation (IGS) is mostly found in publications dealing with vehicle routing problems and network design. Instances usually represent distribution systems with multiple suppliers, capacitated warehouses, capacitated retailers, identical capacitated vehicles and unit-sized items. Such items are to be transported from the suppliers to the warehouses, and subsequently delivered to the retailers by vehicles. The reviewed publications implementing IGS intend to model only important scenarios of a system and in most cases pay particular attention to travel times.

It is interesting to highlight the almost absence of System Dynamics Simulation (SD), which focuses more on the behaviour of the system rather than the individuals composing it. In SD, the real-world processes are represented in terms of stocks and flows. According to Maidstone (2012), DES tends to look at the smaller detail of a system (microscopic), whereas SD tends to take a more overall perspective (macroscopic). As described in Rabelo, et al., (2005), SD is suitable for high level strategic modelling, because (1) it proposes a holistic approach of systems, integrating many subsystems (2) it focuses on policies and system structure (3) it make use of feedback loops to represent the effects of policy decisions.

Finally, we draw the reader's attention to consider the use of hybrid simulation techniques. Indeed, combining simulation techniques could provide better representation of the reality and/or more efficient computing environment by capitalizing on advantages of both techniques. As noticed in works where ABS and DES are combined, authors take advantage of DES to represent complex queuing systems, and of ABS to model different stakeholders that act as independent decision-makers and/or behave as single entities.

\section{ACKNOWLEDGMENTS}


This work is supported by ADEME (Agency for the Environment and Energy Management), La Poste Group, Mairie de Paris, Pomona Group and RENAULT through the Urban Logistics Chair at MINES ParisTech. The authors would like to thank Pr. A. Comi, Pr. P. Cortés, Pr. J. W. Joubert, Dr. M. Marinov, Dr. L. K. de Oliveira, Dr. G. Iacobellis, Pr. J. Gonzalez-Feliu, Pr. G. Gentile and Dr. L. Delaitre for their constructive feedback.

\section{REFERENCES}

Abu-Taieh, E. M. O. (2005). Computer Simulation Using Excel without Programming.

Amaral, R., and Aghezzaf, E. H. (2015). City Logistics and Traffic Management: Modelling the Inner and Outer Urban Transport Flows in a Two-tiered System. Transportation Research Procedia, 297-312.

Anand, N., Meijer, D., Tavasszy, L., and Meijer, S. (2016). A participatory simulation gaming framework for the validation of an agent based model: the case of city logistics. Transportation Research Part C, 71(5216), 1-14.

Barceló, J., Grzybowska, H., and Pardo, S. (2007). Vehicle Routing and Scheduling Models, Simulation and City Logistics. Dynamic Fleet Management Concepts-Systems, Algorithms and Case Studies, (1), 163-195.

Baykasoglu, A., and Kaplanoglu, V. (2011). A multi-agent approach to load consolidation in transportation. Advances in Engineering Software, 42(7), 477-490.

Borshchev, A., \& Filippov, A. (2004). From System Dynamics and Discrete Event to Practical Agent Based Modeling: Reasons, Techniques, Tools. 22nd International Conference of the System Dynamics Society, 25-29 July 2004, 45.

Boussier, J. M., Cucu, T., Ion, L., Estraillier, P., \& Breuil, D. (2009). Goods distribution with electric vans in cities: Towards an agent-based simulation. World Electric Vehicle Journal, 3(1), 597-605.

Bozzo, R., Conca, A., and Marangon, F. (2014). Decision support system for city logistics: Literature review, and guidelines for an ex-ante model. Transportation Research Procedia, 518-527.

Cagliano, A. C., Gobbato, L., Tadei, R., \& Perboli, G. (2014). ITS for e-grocery business: The simulation and optimization of Urban logistics project. Transportation Research Procedia, 3(July), 489-498.

Comi, A., and Rosati, L. (2015). CLASS: a DSS for the analysis and the simulation of urban freight systems. In Transportation Research Procedia 5 (Vol. 5, pp. 132-144). Pages 163-200

Comi, A., Donnelly, R. and Russo,F. ( 2014). Urban Freight Models, In Modelling Freight Transport, Elsevier, Oxford, 2014,

Cortés, P., Muñuzuri, J., Nicolás Ibáñez, J., and Guadix, J. (2007). Simulation of freight traffic in the Seville inland port. Simulation Modelling Practice and Theory, 15(3).

Crainic, T. G., Ricciardi, N., \& Storchi, G. (2004). Advanced freight transportation systems for congested urban areas. Transportation Research Part C: Emerging Technologies, 12(2), 119-137.

De Oliveira, L. K, Oliveira, B. R. P. e, and Correia, V. de A. (2014). Simulation of an Urban Logistic Space for the Distribution of Goods in Belo Horizonte, Brazil. Procedia - Social and Behavioral Sciences, 125, 496-505.

Delaitre, L. (2009). A new approach to diagnose urban delivery areas plans. 2009 International Conference on Computers \& Industrial Engineering, 991-998.

Dieussaert, K., Aerts, K., Steenberghen, T., Maerivoet, S., \& Spitaels, K. (2009). SUSTAPARK: an agent-based model for simulating parking search. AGILE International Conference on Geographic Information Science, Hannover, 1-11.

Dotoli, M., Fanti, M. P., Mangini, A. M., Stecco, G., and Ukovich, W. (2010). The impact of ICT on intermodal transportation systems: A modelling approach by Petri nets. Control Engineering Practice, 18(8), 893-903.

Durand, B., \& Gonzalez-Feliu, J. (2012). Urban Logistics and E-Grocery: Have Proximity Delivery Services a Positive Impact on Shopping Trips? Procedia - Social and Behavioral Sciences, 39, 510-520.

Fanti, M. P., Iacobellis, G., Ukovich, W., Boschian, V., Georgoulas, G., and Stylios, C. (2015). A simulation based Decision Support System for logistics management. Journal of Computational Science, 10, 86-96.

Fatnassi, E. and Chaouachi, J. (2016). Discrete Event Simulation of Loading Unloading Operations in a Specific Intermodal Transportation Context. In Software Engineering Perspectives and Application in Intelligent Systems (pp. 435-444).

Garrido, J. (2011). Introduction to Elementary Computational Modeling: Essential Concepts, Principles, and Problem Solving. CRC Press, 26 October 2011 - 329 pages.

Gattuso, D., Cassone, G. C., Lanciano, C., Placido, V., \& Praticò, M. (2015). A freight urban distribution center design with micro-simulation support for city logistics, WIT Transactions on The Built Environment, Vol 146, @ 2015 WIT Press

Gentile, G., \& Vigo, D. (2013). Movement generation and trip distribution for freight demand modelling applied to city logistics. European Transport, (54), 1-27.

Gonzalez-Feliu, J., Ambrosini, C., Pluvinet, P., Toilier, F., \& Routhier, J. L. (2012). A simulation framework for evaluating the impacts of urban goods transport in terms of road occupancy. Journal of Computational Science, 3(4), 206-215. $10(2), 265-269$.

Gui, S., Zhu, Q., \& Lu, L. (2005). Area logistics system based on system dynamics model. Tsinghua Science and Technology,

Herazo-Padilla, N., Montoya-Torres, J. R., Munoz-Villamizar, A., Isaza, S. N., \& Polo, L. R. (2013). Coupling ant colony optimization and discrete-event simulation to solve a stochastic location-routing problem. In Proceedings of the 2013 Winter Simulation Conference - Simulation: Making Decisions in a Complex World, WSC 2013. 
Hunt, J. D., \& Stefan, K. J. (2007). Tour-based microsimulation of urban commercial movements. Transportation Research Part B 41 (2007), 41, 981-1013.

Joubert, J. W., Fourie, P. J., \& Axhausen, K. W. (2010). Large-Scale Agent-Based Combined Traffic Simulation of Private Cars and Commercial Vehicles. Transportation Research Record: Journal of the Transportation Research Board, 2168(1), $24-32$.

Lebeau, P., Macharis, C., van Mierlo, J., and Maes, G. (2013). Implementing electric vehicles in urban distribution: A discrete event simulation. World Electric Vehicle Journal, 6.

Maggioni, F., Perboli, G., and Tadei, R. (2014). The Multi-Path Traveling Salesman Problem with Stochastic Travel Costs: Building Realistic Instances for City Logistics Applications. Transportation Research Procedia 3, $528-536$.

Maidstone, R. (2012). Discrete Event Simulation, System Dynamics and Agent Based Simulation: Discussion and Comparison. (Whitepaper) 1-6.

Maione, G. (2008). Discrete-Event Dynamic Systems Modelling Distributed Multi-Agent Control of Intermodal Container Terminals. Robotics, Automation and Control, Book.

Makhloufi, R., Cattaruzza, D., Meunier, F., Absi, N., and Feillet, D. (2015). Simulation of Mutualized Urban Logistics Systems with Real-times Management. Transportation Research Procedia, 365-376.

Maria, A. (1997).Introduction to modelling and simulation. In Winter Simulation Conference.

Motraghi, A., and Marinov, M. V. (2012). Analysis of urban freight by rail using event based simulation. Simulation Modelling Practice and Theory, 25, 73-89.

Muñoz-Villamizar, A., and Angel A., J. (2013). A simulation-based algorithm for the integrated location and routing problem in urban logistics. In Proceedings of the 2013 Winter Simulation Conference (pp. 2032-2041).

Nourinejad, M., Wenneman, A., Habib, K. N., \& Roorda, M. J. (2014). Truck parking in urban areas: Application of choice modelling within traffic microsimulation. Transportation Research Part A: Policy and Practice, 64, 54-64.

Nuzzolo, A., Comi, A., \& Rosati, L. (2014). City logistics long-term planning: simulation of shopping mobility and goods restocking and related support systems, International Journal of Urban Sciences (July 2014), 37-41.

ORMS Today Simulation Software Survey, 2015, http://www.orms-today.org/surveys/Simulation/Simulation.html

Ossowski, S., Hernández, J. Z., Belmonte, M. V., Fernández, A., García-Serrano, A., Pérez-de-la-Cruz, J. L., Triguero, F. (2005). Decision support for traffic management based on organisational and communicative multiagent abstractions. Transportation Research Part C: Emerging Technologies, 13(4), 272-298.

Parola, F., \& Sciomachen, A. (2005). Intermodal container flows in a port system network: Analysis of possible growths via simulation models. International Journal of Production Economics, 97(1), 75-88.

Pinto, R., Golini, R., \& Lagorio, A. (2015). Loading / unloading lay-by areas location and sizing: a mixed analytic-Monte Carlo simulation approach. IFAC-PapersOnLine, 49(12), 961-966.

Qiu, Y., Shi, X., \& Shi, C. (2013). A System Dynamics Model for Simulating the Logistics Demand Dynamics of Metropolitans : A Case Study of Beijing. Journal of Industrial Engineering and Management China, 8(3), 783-803.

Qureshi, A., Taniguchi, E., and Yamada, T. (2010). Exact solution for the vehicle routing problem with semi soft times windows and its application. In Procedia Social and Behavioral Sciences, 2, 5931-5943.

Rabelo, L., Helal, M., Jones, A., and H., Min (2005). Enterprise simulation: a hybrid system approach, International Journal of Computer Integrated Manufacturing 18 498-508.

Raychaudhuri, S. (2008). Introduction to Monte Carlo simulation. 2008 Winter Simulation Conference, 91-100.

Readiness, F., \& Team, A. (2012). Survey and Comparison of Modelling Software.

Roca-Riu, M., Fernández, E., \& Estrada, M. (2015). Parking slot assignment for urban distribution: Models and formulations. OMEGA International Journal of Management Science (United Kingdom), 57, 157-175.

Routhier, J.L., Toilier, F., 2007. FRETURB V3, a policy oriented software tool for modelling urban goods movement. In: 11th World Conference on Transport Research.

Schroeder, S., Zilske, M., Liedtke, G., \& Nagel, K. (2012). Towards a Multi-Agent Logistics and Commercial Transport Model: The Transport Service Provider's View. Procedia - Social and Behavioral Sciences, 39, 649-663.

Siebers, P. O., Macal, C. M., Garnett, J., Buxton, D., and Pidd, M. (2010). Discrete-event simulation is dead, long live agentbased simulation! Journal of Simulation, 4(3).

Sonntag, H. (1985) “A Computer Model of Urban Commercial Traffic, in Transport”, Policy and Decision Making, Vol. 3 (2).

Tadei, R., Perboli, G., \& Perfetti, F. (2014). The multi-path Traveling Salesman Problem with stochastic travel costs. EURO Journal on Transportation and Logistics, 1-21

Tamagawa, D., Taniguchi, E., and Yamada, T. (2010). Evaluating city logistics measures using a multi-agent model. In Procedia Social and Behavioral Sciences 2 .

Teoh, T., Kunze, O., and Teo, C.-C. (2016). Methodology to Evaluate the Operational Suitability of Electromobility Systems for Urban Logistics Operations. Transportation Research Procedia, 12(June 2015), 288-300.

Van Duin, J. H. R., van Kolck, A., Anand, N., and Tavasszy, L. órán. A. (2012). Towards an Agent-Based Modelling Approach for the Evaluation of Dynamic Usage of Urban Distribution Centres. Procedia - Social and Behavioral Sciences, 39, $333-348$.

Van Heeswijk, W., Mes, M., \& Schutten, M. (2016). An agent-based simulation framework to evaluate urban logistics scheme. Lecture Notes in Computer Science, 9855:369-383. Sons, Ltd.

Vose, D. (1996). Quantitative risk analysis: a guide to Monte Carlo simulation modelling. Chichester, England: John Wiley \&

Wangapisit, O., Teo, J. S. E., \& Qureshi, A. G. (2014). Multi-agent Systems Modelling for Evaluating Joint Delivery Systems. Procedia - Social and Behavioral Sciences, 125.

Wisetjindawat, W., Sano, K., Matsumoto, S., and Raothanachonkun, P. (2007). Micro-Simulation Model for Modeling Freight Agents Interactions in Urban Freight Movement. 86th Annual Meeting of the Transportation Research Board, 1-20. 